\title{
A Multidrug-resistance Protein (MRP)-like Transmembrane Pump Is Highly Expressed by Resting Murine T Helper (Th) 2, but Not Th1 Cells, and Is Induced to Equal Expression Levels in Th1 and Th2 Cells after Antigenic Stimulation In Vivo
}

\author{
Michael Lohoff, ${ }^{\star}$ Stefan Prechtl, ${ }^{*}$ Frank Sommer, ${ }^{*}$ Martin Roellinghoff, ${ }^{*}$ Edgar Schmitt, ${ }^{\ddagger}$ Gernot Gradehandt, ${ }^{\ddagger}$ Peter Rohwer, ${ }^{\S}$ \\ Brenda D. Stride," Susan P.C. Cole, and Roger G. Deeley\| \\ *Institut für Klinische Mikrobiologie und Immunologie, University of Erlangen, 91054 Erlangen, Germany; ${ }^{\ddagger}$ Institut für Immunologie, \\ University of Mainz, 55101 Mainz, Germany; ${ }^{\S}$ Institut für Klinische Immunologie, University of Erlangen, 91056 Erlangen, Germany; and \\ "Cancer Research Laboratories, Queen's University, Kingston, K7L 3N6, Canada
}

\begin{abstract}
A transmembrane pump for organic anions was identified in resting murine $\mathrm{T}$ helper (Th) 2 , but not $\mathrm{Th} 1$ lymphocyte cell clones, as revealed by extrusion of a fluorescent dye. Dye extrusion inhibition studies suggested that the pump may be the multidrug-resistance protein (MRP). The different expression of the pump in resting Th1 and Th2 cell clones correlated with their respective levels of MRP mRNA. The pump was inducible in Th1 cells by antigenic stimulation in vitro leading to equal expression in activated Th1 and Th2 cell clones. This suggested that dye extrusion might allow the detection of Th2 (resting or activated) or of activated Th1 cells ex vivo based on a functional parameter. To test this, mice were infected with Leishmania major parasites to activate $L$. major-specific $T$ cells of either Th1 (C57BL/6 mice) or Th2 (BALB/c mice) phenotype: 2-3\% of CD4+ lymph node $T$ cells of both strains of mice extruded the dye, defining a cell subset that did not coincide with subsets defined by other activation markers. Fluorescence-activated cell-sorting revealed that the lymphokine response (Th1 or Th2, respectively) to $L$. major antigens was restricted to this dye-extruding subset. (J. Clin. Invest. 1998. 101:703-710.) Key words: multidrug-resistance protein $\bullet T$ helper $1 \cdot \mathrm{T}$ helper $2 \cdot$ leishmaniasis
\end{abstract}

\section{Introduction}

The fluorescent dye Fluo-3-AM readily passes through cell membranes due to its estered lipophilic tail. After cleavage by cell-membrane esterases, the more hydrophilic free anion is normally sequestered in the cytoplasm $(1,2)$. Previously, we have described a CD4+ T helper $2(\mathrm{Th} 2)^{1}$ lymphocyte cell

Address correspondence to Michael Lohoff, Institut für Klinische Mikrobiologie und Immunologie, University of Erlangen, Wasserturmstr. 3, 91054 Erlangen, Germany. Phone: 49-9131-85-3640; FAX: 49-9131-85-2573.

Received for publication 5 June 1997 and accepted in revised form 1 December 1997.

1. Abbreviations used in this paper: CsA, cyclosporin A; LN, lymph nodes; LT, leukotriene; MRP, multidrug-resistance protein; PE, phycoerythrin; PPD, purified protein derivative; $\mathrm{SN}$, culture supernatant; $\mathrm{Th}, \mathrm{T}$ helper.

J. Clin. Invest.

(C) The American Society for Clinical Investigation, Inc. 0021-9738/98/02/0703/08 \$2.00

Volume 101, Number 3, February 1998, 703-710

http://www.jci.org clone (secreting IL-4, IL-5, and IL-6, but not IL-2 or IFN- $\gamma$ ) able to efflux free anionic Fluo-3 from the cell using an energydependent transport system for organic anions (3). Dye extrusion was prevented by probenecid (3), an inhibitor of anion transport, as well as by cyclosporin A (CsA). This led us to speculate that the Th2 cell clone might express a transmembrane pump possibly related to either P-glycoprotein or multidrug-resistance protein (MRP), both of which mediate multidrug resistance in cancer cells $(4,5)$. Such an idea was further stimulated by reports from several laboratories showing a relative insensitivity of Th2 cells to a number of compounds, such as prostaglandin $E_{2}$ or cholera toxin $(6,7)$. This insensitivity could potentially be explained by enhanced transport of either of these compounds or of their metabolites out of the cell. In contrast, Th1 cells were always found to be more sensitive to the same compounds $(6,7)$.

Therefore, we set out to determine whether the presence of a Fluo-3-extruding pump was a general characteristic of Th2 cells and whether or not a similar pump was also present in Th1 cells. To investigate these possibilities, we used murine $\mathrm{T}$ cell clones in vitro, as well as an in vivo model, experimental murine leishmaniasis (for review see reference 8). This latter model allowed the study of both Th1 and Th 2 cells in vivo, because infection leads to expansion of parasite-specific Th1 cells in the resistant $\mathrm{C} 57 \mathrm{BL} / 6$ mouse strain and of $\mathrm{Th} 2$ cells in the susceptible BALB/c strain.

\section{Methods}

Reagents. Verapamil, probenecid, leukotriene (LT) $\mathrm{B}_{4}, \mathrm{LTC}_{4}$, and Fluo-3-AM were purchased from Sigma (Deisenhofen, Germany). CsA and PSC833 were kindly provided by Dr. Richardson (Sandoz, Basel, Switzerland). MK571 was kindly provided by Dr. Ford-Hutchinson (Merck-Frosst Inc., Quebec, Canada).

$T$ cell lines. The following Th1 cell lines and clones were used: B10BI and F3.1, specific for bovine insulin, LNC-2 specific for Mycobacterium tuberculosis purified protein derivative (PPD) and C57/4 specific for LmAg, a Leishmania major antigen preparation (9-12). Th2 cell lines and clones used were D10G4.1 specific for ovalbumin, BEL-16 and L1/1 specific for LmAg, and LNC-4 specific for PPD (10-14). The in vitro propagation of these T cells has been described (9). Briefly, $5 \times 10^{5}$ cells/well were restimulated every 3 wk in 12-well tissue culture plates (Costar, Cambridge, MA) with syngeneic, irradiated $(25 \mathrm{~Gy})$ spleen cells $\left(5 \times 10^{6} /\right.$ well $)$ and antigen in a total volume of $2 \mathrm{ml}$ of medium, supplemented as described (15). $3 \mathrm{~d}$ after restimulation, the cells were split and culture supernatant (SN; $10 \%)$ of the cell line X63Ag8-653/IL-2 (16) was added as a crude source of recombinant murine IL-2. Thereafter, IL-2 was added once per week. Cells were routinely used for the experiments 3 wk after their final antigenic restimulation.

Purification of $C D 4+T$ cells by magnetic cell sorting $\left(M A C S^{\circledR}\right)$. $\mathrm{BALB} / \mathrm{c}$ and $\mathrm{C} 57 \mathrm{BL} / 6$ mice at 4-6 wk of age were purchased from 
Charles River (Sulzfeld, Germany). $2 \times 10^{7}$ L. major promastigotes were injected into both hind footpads of the mice, as described (15). 3 wk later, mice were killed, the popliteal lymph nodes (LNs) were removed, and single cell suspensions were obtained. The CD4+ T cells among these LN cells were then purified by negative selection using the MACS ${ }^{\circledR}$ system (Miltenyi Biotec GmbH, Bergisch Gladbach, Germany) and anti-CD45R (B220, a pan B cell marker), anti-CD8, and anti-CD11 antibodies (Miltenyi Biotec $\mathrm{GmbH}$; all conjugated to magnetic beads) according to the manufacturer's specifications (17). After purification, $>95 \%$ of the cells were $\mathrm{CD} 4+$. These cells were labeled with Fluo-3-AM.

Western blots. Spleen cells from normal BALB/c mice were depleted of CD4+ T cells using anti-CD4 antibodies conjugated to magnetic beads and the MACS ${ }^{\circledR}$ system, as described above. After this step, the cells contained $<0.5 \% \mathrm{CD} 4+\mathrm{T}$ cells. These cells were irradiated (20Gy) and used $\left(5 \times 10^{6} /\right.$ well $)$ to stimulate resting LNC-2 cells $\left(5 \times 10^{5} /\right.$ well $)$ with PPD $(30 \mu \mathrm{g} / \mathrm{ml})$ in a total volume of $3 \mathrm{ml}$ of medium for $48 \mathrm{~h}$. Thereafter, cells were harvested and depleted of splenic cells using anti-CD45R, anti-CD8, and anti-CD11 antibodies (all conjugated to magnetic beads) and the MACS ${ }^{\circledR}$ system, as above. After purification, $\mathrm{FACS}^{\circledR}$ analysis revealed that $>92 \%$ of the cells were LNC-2 cells based on forward/side scatter characteristics and CD4 expression. These cells, along with resting LNC-2 Th1 and resting L1/1 Th2 cells were washed twice in PBS. The cell pellets were shock-frozen. The levels of expression of murine MRP and P-glycoprotein in these cells were determined by immunoblot analysis of membrane protein fractions, as previously described $(18,19)$. Briefly, membrane-enriched fractions were prepared and membrane proteins were separated by SDS-PAGE followed by transfer to Immobilon-P polyvinylidene difluoride membranes (Millipore, Bedford, MA). Murine MRP was detected using the MRP-specific monoclonal antibody, MRPr1 (20). Antibody binding was detected with horseradish peroxidase-conjugated goat anti-rat antibody (Chromatographic Specialties, Brockville, Canada) and enhanced chemiluminescence detection (DuPont NEN, Boston, MA). Blots were reprobed with the P-glycoprotein specific mAb C219 (21) after stripping in $2 \% \mathrm{SDS} / 100 \mathrm{mM}$ 2-mercaptoethanol/ $62.5 \mathrm{mM}$ Tris, $\mathrm{pH} 6.7$, for $30 \mathrm{~min}$ at $50^{\circ} \mathrm{C}$. In this case, the secondary antibody used was horseradish peroxidase-conjugated goat anti-mouse antibody (Chromatographic Specialties). As a positive control, the 8226/Dox40 cell line expressing both MRP and P-glycoprotein $(19,22,23)$ was used.

Fluorescence staining of $T$ cells. For labeling of T cells with Fluo3-AM and secretion of the Fluo-3 anion, a procedure was used that is essentially described in detail elsewhere (3). However, in this study, labeling with Fluo-3-AM was performed in the presence of CsA (25 $\mu \mathrm{mol})$ instead of probenecid. After labeling, the cells were incubated at $37^{\circ} \mathrm{C}$ (in the presence or absence of different inhibitors) for $60 \mathrm{~min}$ to allow for secretion of the Fluo-3 anion. After this step, $\mathrm{T}$ cell clones were analyzed in a FACScan ${ }^{\circledR}$ (Becton-Dickinson, Heidelberg, Germany) using Lysis II software. In contrast, the MACS ${ }^{\circledR}$-sorted cells were stained in one additional step with anti-CD4 antibodies conjugated to phycoerythrin (PE; Medac, Hamburg, Germany), analyzed, and sorted using an EPICS ELITE ${ }^{\circledR}$ (Coulter, Krefeld, Germany) and the ELITE software.

For staining of the IL-2 receptor $\alpha$ chain (CD25), T cell clones $\left(10^{6}\right.$ cells) were incubated on ice for $30 \mathrm{~min}$ in $100 \mu \mathrm{l}$ PBS containing $1 \%$ FCS and $10 \mu \mathrm{l} \mathrm{SN}$ of the hybridoma 7D4 (24). After washing, counterstaining was performed using FITC-conjugated donkey antirat IgG (Dianova, Hamburg, Germany) diluted in PBS/1\% FCS. Subsequently, the fluorescence of the cells was analyzed on a FACScan ${ }^{\circledR}$.

For three-color fluorescence analysis, LN cells of L. major-infected mice were labeled with Fluo-3-AM and incubated to allow for Fluo-3 efflux, as described above. Thereafter, the cells were incubated for $30 \mathrm{~min}$ at $4^{\circ} \mathrm{C}$ with crude SNs of hybridomas secreting antibodies against one of the following markers: CD25, CD44, CD45RB, CD62L, or CD69 (25-29). After washing, the cells were incubated with biotinylated mouse anti-rat IgG $(1 \mu \mathrm{g} / \mathrm{ml}$; Dianova) and washed. Thereafter, remaining binding sites of anti-rat $\mathrm{IgG}$ were absorbed by incubation with polyclonal rat $\operatorname{IgG}(30 \mu \mathrm{g} / \mathrm{ml})$. Finally, anti-rat antibodies were visualized by streptavidin conjugated to tricolor (Medac), and cells were counterstained by anti-CD4-PE and analyzed on a FACScan ${ }^{\circledR}$.

$T$ cell stimulation in vitro. For restimulation in vitro, either LN cells obtained after MACS ${ }^{\circledR}$ sorting ("MACS ${ }^{\circledR}$-only"), CD4+ Fluo-3extruding LN cells sorted by MACS ${ }^{\circledR}$ and the EPICS ELITE ${ }^{\circledR}$ ("Fluo3 dull"), similarly sorted dye nonextruding cells ("Fluo-3 bright"), or MACS $^{\circledR}$-sorted Fluo-3-labeled LN cells mock-sorted in the EPICS ELITE $^{\circledR}$ ("mock-sorted") were used. These cells $\left(7 \times 10^{3} /\right.$ well $)$ were cultured in 96-well flat-bottomed microtiter plates (Nunc, Wiesbaden, Germany) with syngeneic, irradiated $(25 \mathrm{~Gy})$ spleen cells $(3 \times$ $10^{5} /$ well) with and without the $L$. major antigen preparation $\operatorname{LmAg}(3 \times$ $10^{5} /$ well) (11) in a total volume of $200 \mu \mathrm{l}$. After $48 \mathrm{~h}$, the SNs were harvested and tested for the presence of IL- 4 and IFN- $\gamma$ using commercial ELISA kits (PharMingen, Hamburg, Germany) performed according to the manufacturer's specifications.

Limiting dilution analysis. T cells obtained either after MACS ${ }^{\circledR}$ sorting or after FACS ${ }^{\circledR}$-sorting of Fluo-3 dull CD4+ cells were pipetted in graded numbers into 96-well flat-bottomed microtiter plates (Nunc) in the presence of $10^{5}$ irradiated (25Gy) syngeneic spleen cells, $\operatorname{LmAg}\left(3 \times 10^{5} /\right.$ well $)$, and SN $(10 \%)$ of each of the cell lines X63Ag8-653/IL-2 and X63Ag8-653/IL-4 (16) in a total volume of $200 \mu \mathrm{l}$ medium and incubated at $37^{\circ} \mathrm{C}$. After $13 \mathrm{~d}, 100 \mu \mathrm{l}$ were replaced by fresh IL-2/IL-4 containing SN. In addition, cells were restimulated with antigen after $7 \mathrm{~d}$ of culture by adding into the wells $10^{5}$ irradiated (25Gy) syngeneic spleen cells, $\mathrm{LmAg}\left(3 \times 10^{5} /\right.$ well $)$, and IL-2/IL-4 containing SN (10\%). After 2 wk of culture, wells were extensively washed and the contents of each well were split into three, one of which contained no further additions, one $1.5 \times 10^{5}$ irradiated (25Gy) syngeneic spleen cells, and one $1.5 \times 10^{5}$ irradiated $(25 \mathrm{~Gy})$ syngeneic spleen cells plus $\operatorname{LmAg}\left(3 \times 10^{5} /\right.$ well $)$. After $48 \mathrm{~h}$, the SN were harvested and tested for the presence of IL- 4 or IFN- $\gamma$ by ELISA, as described above. Wells were considered to be positive if the optical density exceeded the mean values obtained for control wells (containing spleen cells only) by two SD. Antigen reactivity was defined as a $>30 \%$ increase of cytokine production in response to spleen cells plus $\mathrm{LmAg}$ as compared with stimulation with spleen cells alone. According to Poisson statistics (30), the original cell dilution that gave rise to $37 \%$ negative wells was considered to contain one antigen-reactive $\mathrm{T}$ cell per well.

Northern blot analysis. Total RNA from Th1 and Th2 cell clones was harvested using the RNeasy kit (Qiagen, Hilden, Germany) according to the manufacturer's instructions. Northern blotting using a murine-specific cDNA probe was carried out as described previously (31). The Northern blots were scanned using an Epson GT 8000 and ScanPack software (Biometra, Göttingen, Germany).

\section{Results}

Analysis of the expression of the Fluo-3-extruding pump in resting Th1 and Th2 cell clones. Previously, we reported that the Th 2 cell clone L1/1 expresses a transmembrane transporter able to extrude the Fluo-3 anion out of the cytoplasm (3). To test if expression of this molecule was a more general feature of $\mathrm{T}$ cell clones, four Th1 and four Th2 cell clones, each in a resting state (i.e., $3 \mathrm{wk}$ after the final antigenic restimulation) were labeled with the lipophilic ester Fluo-3-AM. Thereafter, the cells were incubated for $60 \mathrm{~min}$ at $37^{\circ} \mathrm{C}$ to allow for extrusion of the cleaved anion Fluo-3 by the transporter. Finally, the fluorescence intensities of these cells (closed graphs) and of control cells incubated in parallel at $4^{\circ} \mathrm{C}$ after labeling (open graphs) were determined (Fig. 1). The results indicated that all four Th2 cell clones were able to extrude Fluo-3, whereas the four Th1 cell clones were either unable to extrude the dye or did so at a very low rate (more than 10 separate experiments). 


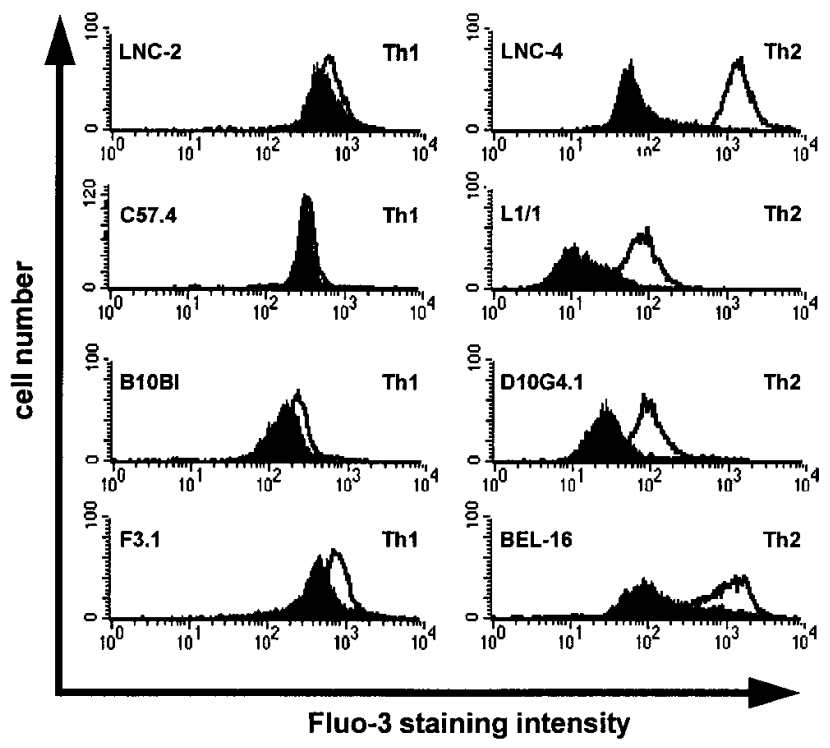

Figure 1. A Fluo-3-extruding pump differentiates between resting Th1 and Th 2 cell clones. T cells were labeled with Fluo-3 3 wk after antigenic stimulation and were incubated for $60 \mathrm{~min}$ at $37^{\circ} \mathrm{C}$ (filled histograms) or $4^{\circ} \mathrm{C}$ (open histograms) to allow dye extrusion to occur. Thereafter, cell fluorescence was analyzed by FACS ${ }^{\circledR}$.

In all Th2 cell clones, extrusion was blocked by CsA (data not shown).

Investigation of the identity of the Fluo-3-extruding pump. Inhibition of the transport of some organic anions by probenecid and CsA has been reported for both P-glycoprotein and MRP (32-36). Consequently, we examined the ability of these and several other compounds which are thought to inhibit P-glycoprotein or MRP to block Fluo-3 extrusion by the Th2 cell clone L1/1 (Fig. $2 A$ ). In addition to probenecid (3) and CsA, both verapamil and PSC888, a nonimmunosuppressive pharmacological analogue of CsA, completely blocked Fluo-3 extrusion. However, the potency of CsA was higher than that of PSC833, a characteristic previously reported for MRP, but not for P-glycoprotein $(32,33,36)$. To examine the possibility that the pump was MRP or a similar transporter, we tested the ability of the compound MK571 to inhibit efflux of Fluo-3. MK571, a $\mathrm{LTD}_{4}$ receptor antagonist, has been shown to inhibit MRP also (36). This compound effectively blocked efflux at a concentration of $25 \mu \mathrm{mol}$. Likewise, efflux could be inhibited by $\mathrm{LTC}_{4}$, a known high-affinity substrate of MRP (36), but not by $\mathrm{LTB}_{4}$ which is transported very poorly by the protein. Overall, the results suggest that the Fluo-3-extruding pump has a specificity more similar to that of MRP than of P-glycoprotein.

To investigate the level of MRP mRNA expression, total RNA was prepared from part of the Th1 and Th2 cell clones in a resting state and Northern blotting was used to analyze levels of MRP mRNA. Fig. $2 B$ demonstrates that MRP mRNA could be detected and that its level correlated with the capacity of cells to extrude Fluo-3. Strong expression was noted in L1/1 Th2 cells with somewhat lower expression in D10G4.1 Th2 cells. Consistent with this result, L1/1 Th2 cells always extruded Fluo-3 slightly faster than D10G4.1 Th2 cells. In contrast, expression of MRP mRNA was very low in B10BI and hardly detectable in LNC-2 Th1 cells (Fig. 2 B) as well as in F3.1 Th1 cells (not shown). Thus, the data obtained by Northern blot analysis are consistent with the possibility that the Fluo-3-extruding pump is MRP.

Fluo-3 extrusion by activated Th1 and Th2 cell clones. The difference in Fluo- 3 extrusion by Th1 and Th 2 cell clones was clearly a characteristic of resting cells, because $48 \mathrm{~h}$ after antigenic restimulation Th1 cell clones gained the capacity to extrude Fluo-3 at a rate similar to that of Th2 cell clones (Fig. 3). Antigenic restimulation did not change the capacity of Th2 cell clones to extrude the dye (not shown). During a culture period of $3 \mathrm{wk}$ in medium containing IL-2, but not antigen,

A

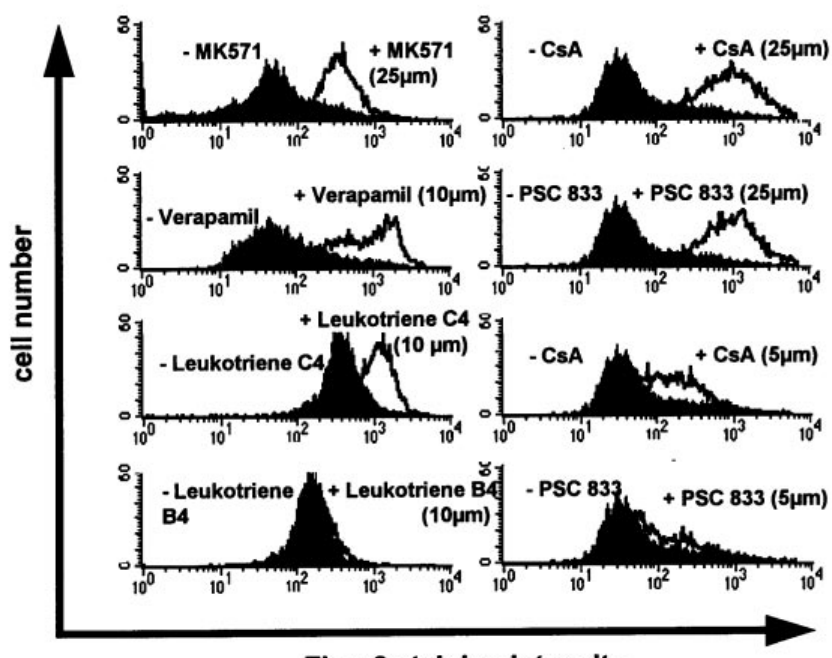

Fluo-3 staining intensity

B

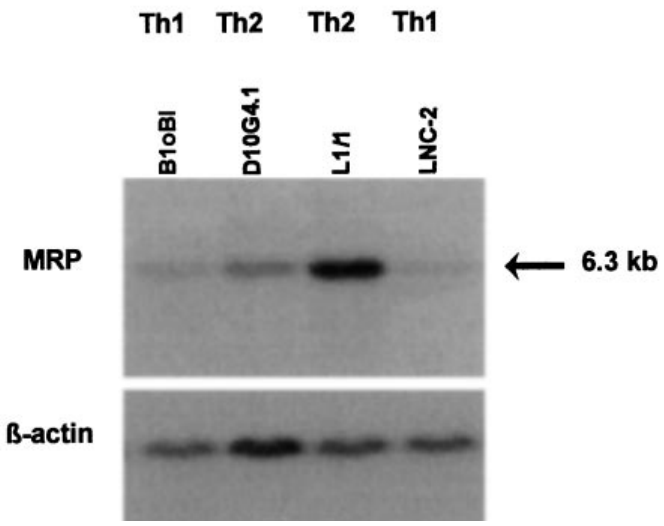

Figure 2. The Fluo-3-extruding pump may be identical to MRP. $(A)$ L1/1 T cells were labeled with Fluo-3 and allowed to extrude the dye for $60 \mathrm{~min}$, as described for Fig. 1. Incubation for dye extrusion occurred in the presence or absence of inhibitors used at the concentrations indicated. Since the data were accumulated from different experiments, each panel also includes the profile of L1/1 cells that extruded Fluo-3 in the absence of inhibitor in the respective experiment. (B) Northern blot analysis of RNA obtained from resting T cells of the clones L1/1, D10G4.1, LNC-2, and B10BI, probed with a cDNA fragment of murine MRP or with a cDNA for $\beta$-actin for comparison. 


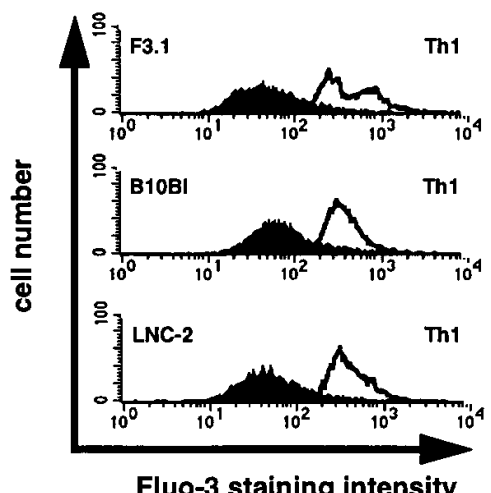

Fluo-3 staining intensity
Figure 3. Antigen-activated Th1 cell clones extrude Fluo-3. Th1 cell clones were restimulated by syngeneic spleen cells and antigen. Extrusion of Fluo-3 was analyzed $48 \mathrm{~h}$ later, as described for Fig. 1. Separation of the Th1 cells and remaining spleen cells was obtained on the basis of different forward and side scatter characteristics.

Th1, but not Th2 cell clones again lost the capacity to extrude Fluo-3 (not shown). Culture of Th1 cells in the presence of IL-4 did not alter their potential to extrude Fluo-3. These latter two observations clearly show that the difference in the capacity to extrude Fluo-3 was not caused by different in vitro culture conditions of the respective $\mathrm{T}$ cell clones.

Like dye extrusion by resting $\mathrm{T}$ cell clones, upregulation of the dye-extruding pump by activated Th1 cells correlated with MRP expression. This was confirmed in experiments where the expression of MRP was tested at the protein level by Western blotting (Fig. 4). Again, relatively high levels of MRP were detected in resting Th2, with severalfold lower levels in resting Th1 cells. However, after antigenic restimulation, Th1 cells clearly increased expression of MRP. In contrast, no expression of P-glycoprotein was detected in Th1 or Th2 cells (Fig. 4), although P-glycoprotein in 8226/Dox40 cells used as a positive control for P-glycoprotein expression was easily demonstrated.

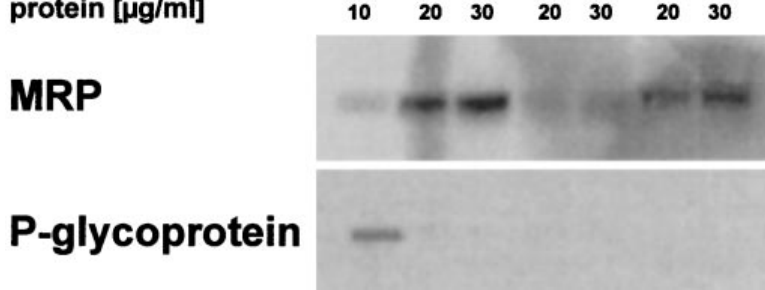

Figure 4. Analysis of MRP protein. Membrane preparations of resting or antigen-activated LNC-2 Th1 cells, resting L1/1 Th2 cells, or control 8226/Dox40 cells were prepared, as described in Methods. The samples containing the indicated amounts of protein were run on a SDS polyacrylamide gel, blotted onto a nitrocellulose membrane, and probed for MRP with $\mathrm{mAb}$ MRPr1 or for P-glycoprotein with $\mathrm{mAb}$ C219.

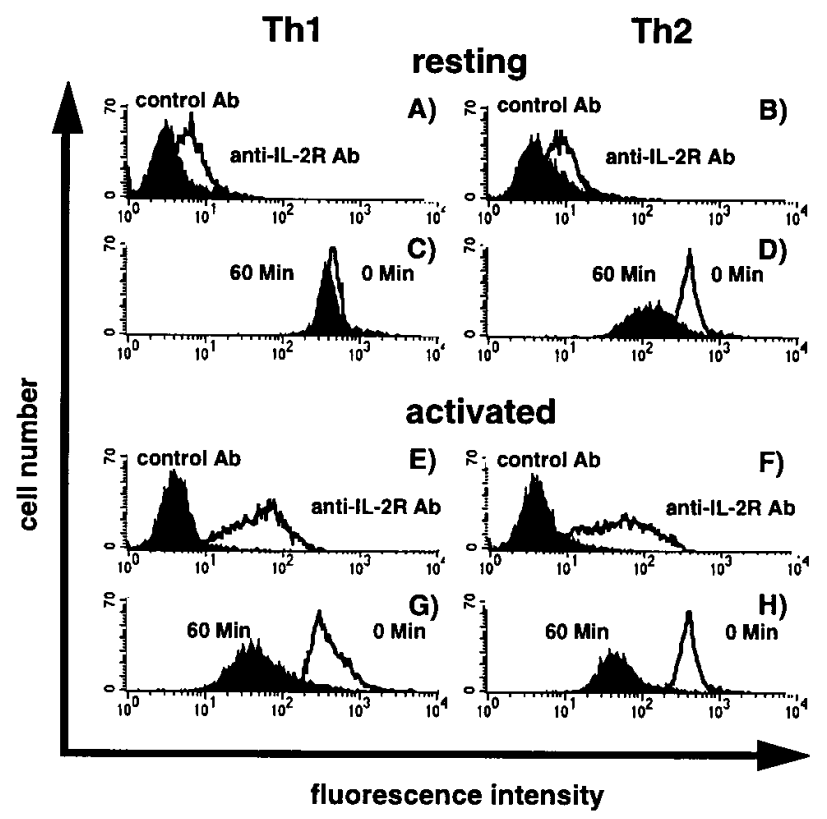

Figure 5. Comparison of the activation status of resting Th1 and Th2 cell clones. Th1 (left) or Th2 cell clones (right), either resting $(A-D)$ or activated for $48 \mathrm{~h}$ by antigen $(E-H)$ were labeled with Fluo-3 and analyzed for Fluo-3 extrusion, as described for Fig. 1. In parallel, cells were also stained for expression of CD25. Where indicated, staining was performed using an isotype-matched control antibody instead of anti-CD25.

The difference in Fluo-3 extrusion of "resting" Th1 and Th2 cell clones could have been caused by a different residual activation status of these cells. To exclude this possibility, the capacity of Th1 and Th 2 cells to extrude Fluo-3 was correlated with their expression of the T cell activation marker CD25. As shown in Fig. 5, CD25 expression was comparably upregulated in $\mathrm{Th} 1$ and $\mathrm{Th} 2$ cell clones $48 \mathrm{~h}$ after antigenic restimulation relative to the similar low level of expression in resting Th1 and Th 2 cells. Therefore, the activation status of the Th1 and Th2 cells was comparable. Despite this, resting but not antigen-activated Th1 and Th2 cell clones again clearly differed with respect to their capacity to extrude Fluo-3.

Identification of Fluo-3-extruding Th1 and Th2 cells in vivo. The finding that activated Th1 and both resting as well as activated Th2 cell clones expressed the Fluo-3-extruding pump suggested that extrusion of the dye might provide a means to sort Th1 or Th 2 cells ex vivo. To pursue this idea, we infected mice subcutaneously with L. major promastigotes. This infection creates a self-healing sore and expansion of parasite-specific Th1 cells in the lesion-draining LN of resistant C57BL/6 mice (for review see reference 8). In contrast, infection of susceptible BALB/c mice results in expansion of Th2 cells and systemic spread of the parasites (8). In both mouse strains, the infection leads to a $>30$-fold increase in cell number in the lesion-draining LN. Nevertheless, the frequency of parasite-specific Th cells is very low. The antigen specificity of the vast majority of Th cells in these enlarged $\mathrm{LN}$ is unknown. During the initial 4 wk of infection, the load of parasites (and their antigens) is high in both mouse strains and the parasitespecific Th1 and Th2 cells can be considered to be activated rather than resting. 


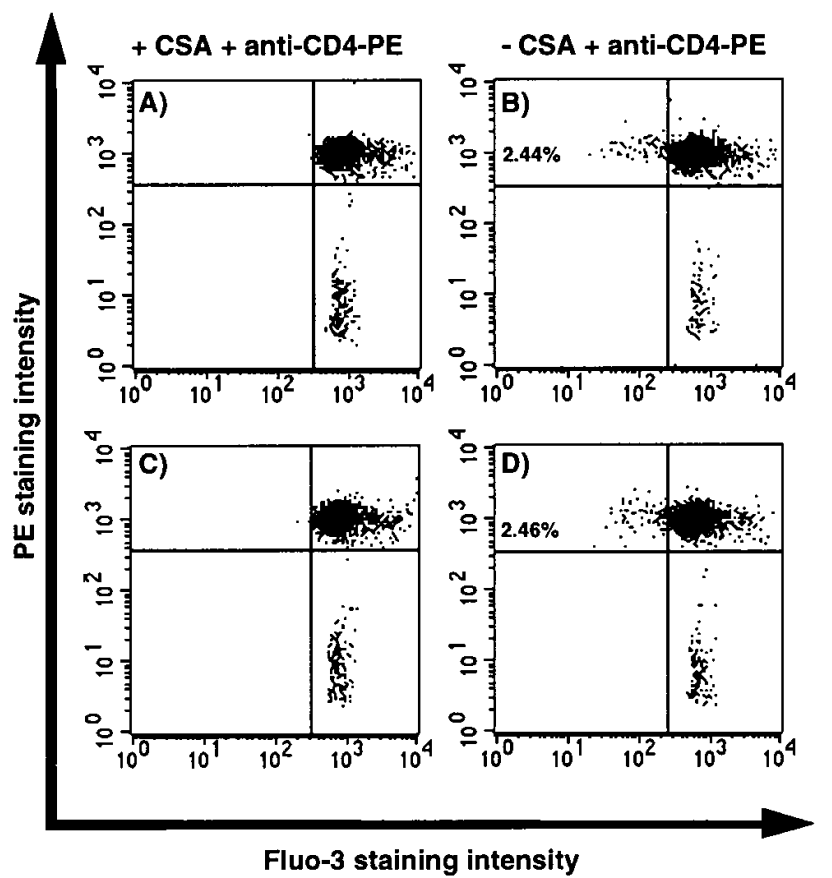

Figure 6. Fluo-3 extrusion by CD4+ lymphocyte subsets in the draining $\mathrm{LN}$ of $L$. major-infected mice. BALB/c mice or C57BL/6 mice were infected with $2 \times 10^{7} \mathrm{~L}$. major promastigotes in the hind footpads. 3 wk later, the $\mathrm{CD} 4+\mathrm{T}$ cells of the draining popliteal LNs were selected by MACS ${ }^{\circledR}$. Thereafter, the cells were loaded with Fluo-3 and processed for dye extrusion, as described for Fig. 1. Finally, cells were stained with anti-CD4-PE and cell fluorescence was analyzed ( $A$ and $B, \mathrm{BALB} / \mathrm{c} ; C$ and $D, \mathrm{C} 57 \mathrm{BL} / 6$ ). Where indicated, cells were incubated with CsA $(25 \mu \mathrm{M})$ to block dye extrusion.

3 wk after infection, the lesion-draining popliteal LNs from susceptible and resistant mice were removed. Single cell suspensions of the $\mathrm{LN}$ were enriched for $\mathrm{CD} 4+\mathrm{T}$ cells by MACS $^{\circledR}$, labeled with Fluo-3, and incubated for $1 \mathrm{~h}$ at $37^{\circ} \mathrm{C}$ to allow for dye extrusion to occur. Thereafter, the cells were counterstained with PE-conjugated anti-CD4 antibodies and analyzed by $\mathrm{FACS}^{\circledR}$ (Fig. 6). Within LN cells of both types of mice, two populations of $\mathrm{CD} 4+\mathrm{T}$ cells could be resolved on the basis of their ability to extrude Fluo-3. In five separate experiments, the frequency of dye-extruding cells in both types of mice ranged from 2 to $10 \%$ of total CD4+ T cells and mostly was between 2 and $4 \%$ (Fig. 6, right panels, upper left quadrants). Dye extrusion from the competent population was prevented by CsA (Fig. 6, left panels). In kinetic experiments, it was similarly shown that Fluo-3-extruding cells are induced over time during an infection with $\mathrm{L}$. major. The relative numbers of dye-extruding BALB/c cells (percentage of total CD4+ $\mathrm{T}$ cells) in one representative experiment were as follows: day $0,0.2 \%$; day $7,1.6 \%$; day $14,4.9 \%$; and day $21,8.9 \%$.

The dye-extruding (Fluo-3 dull) and dye nonextruding (Fluo-3 bright) CD4+ T cells of L. major-infected C57BL/6 and $\mathrm{BALB} / \mathrm{c}$ mice were sorted and, in comparison to mocksorted cells, were restimulated in vitro with syngeneic spleen cells and $L$. major antigens. 48-h culture SNs were tested for IL-4 and IFN- $\gamma$ (Fig. $7 A$ ). Sorting of dye-extruding cells strongly selected for lymphokine secretion in response to $L$. major antigens. Importantly, enhanced cytokine secretion by Fluo-3 dull cells was also observed compared with cells that had not been stained with Fluo-3 (MACS ${ }^{\circledR}$-only) ruling out the possibility that enhanced cytokine production in Fluo-3 dull over Fluo-3 bright cells was solely due to a toxic interference of Fluo-3 with cell metabolism. In addition, Fluo-3 bright cells produced IL-2 in the same order of magnitude $(251 \mathrm{pg} / \mathrm{ml})$ as Fluo-3 dull cells after stimulation with phorbol esters and ionomycin $(520 \mathrm{pg} / \mathrm{ml})$. The relative amounts of IL-4 and IFN- $\gamma$ demonstrated that $L$. major-specific dye-extruding C57BL/6 CD4+ T cells were of Th1 phenotype (high IFN- $\gamma$, low IL-4), while the respective $\mathrm{BALB} / \mathrm{c}$ cells were of Th2 phenotype (low IFN- $\gamma$, high IL-4). Therefore, it is concluded that in vivo activated Th1 and Th2 cells have the capacity to extrude Fluo-3,
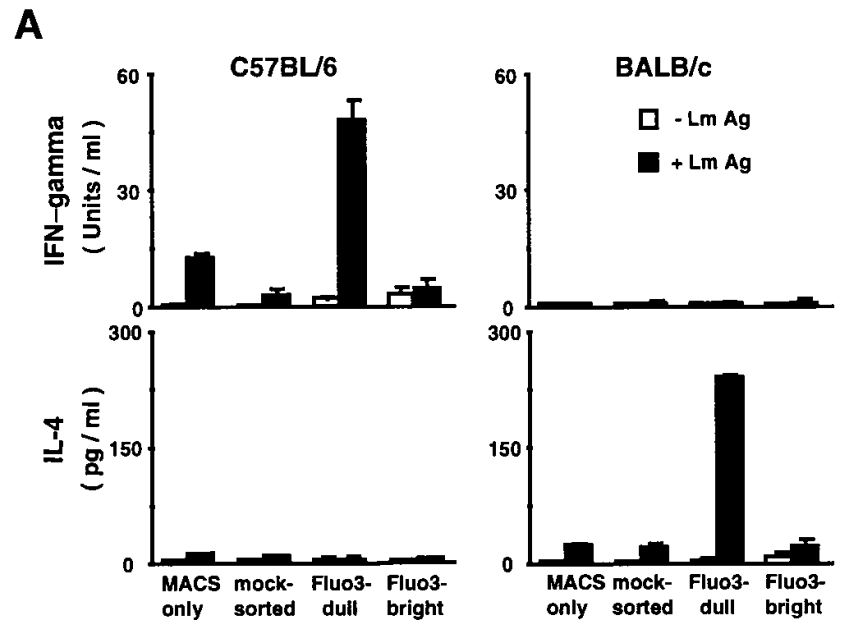

B

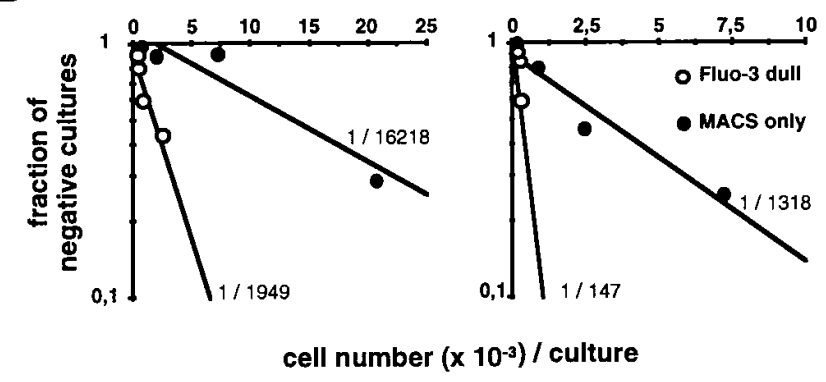

Figure 7. Lymphokine production by CD4+ lymphocyte subsets in the draining LNs of L. major-infected mice. $(A)$ Cell subsets located in the upper left quadrants of the right two panels in Fig. 6 (Fluo-3 dull) and obtained from pooled $\mathrm{LN}$ of five mice were sorted and restimulated $\left(7 \times 10^{3} /\right.$ well $)$ with syngeneic spleen cells $\left(3 \times 10^{5} /\right.$ well $)$ in the presence or absence of $\operatorname{LmAg}\left(3 \times 10^{5} /\right.$ well $)$, as indicated. For comparison, Fluo-3 bright, Fluo-3-stained mock-sorted cells, and MACS $^{\circledR}$-sorted cells without Fluo-3 staining (MACS ${ }^{\circledR}$-only) were also tested. $48 \mathrm{~h}$ later, SNs were harvested and tested for the presence of IFN- $\gamma$ or IL-4 by ELISA. (B) MACS ${ }^{\circledR}$-only cells and Fluo-3 dull cells were tested in limiting dilution analyses for the frequency of CD4+ T cells reactive to L. major antigens, as described in Methods. The fraction of negative wells per cell number tested is compared with the number of cells in these wells; in addition, the frequency of reactive cells calculated according to Poisson statistics (24) is also given. 
confirming the results obtained for in vitro cultured Th1 and Th2 cell clones.

To investigate whether enhanced cytokine production in bulk sorted cells correlated with an increase in the frequency of $L$. major-specific $\mathrm{T}$ cells, limiting dilution analyses were performed that compared these frequencies within the Fluo-3 dull and the MACS ${ }^{\circledR}$-only cell populations. The MACS ${ }^{\circledR}$-only cells were chosen for comparison because they already had a purity of CD $4+$ cells of $>95 \%$ and because these cells lacked possible effects of Fluo-3 on the function of the cells. The cells were diluted immediately after sorting to avoid interactions of the cells before this step. After two cycles of restimulation with antigen-presenting cells and L. major antigens plus cytokines, the frequency of cells producing IFN- $\gamma$ (C57BL/6 LN cells) or IL-4 (BALB/c LN cells) in response to L. major antigens was determined. For each mouse strain, two independent experiments with similar outcome were performed. Data for one such experiment are shown in Fig. 7 B. In both mouse strains, the frequency of $L$. major-reactive CD4+ T cells was increased about ninefold in the Fluo-3 dull compared with the mock-sorted cells. This clearly indicates that sorting according to Fluo-3 efflux enriched the frequency of $L$. major-reactive CD4+ $\mathrm{T}$ cells. The very low frequency of parasite-specific CD4+ Th cells in both strains of mice also suggests that the Fluo-3-extruding cells are composed not only of parasite-specific Th cells, but rather encompass other activated Th cells of unknown antigenic specificity as well.

Fluo-3 extrusion defines a novel unique subpopulation of CD4+ cells. To exclude the possibility that sorting according to Fluo-3 extrusion might simply imitate sorting according to expression of other previously known activation markers, we analyzed simultaneously the capacity of CD4+ LN cells from L. major-infected BALB/c mice to extrude Fluo-3 and to express a panel of activation markers, namely of CD25high (hi), CD44(hi), CD45RBlow (lo), CD62L(lo), and CD69(hi) (2529). The results (gated on cells staining positive for CD4 in the third color) are depicted in Fig. 8 and show the staining intensity for the respective activation marker ( $y$ axis) plotted against the Fluo-3 staining intensity ( $x$ axis). In each panel, the area containing activated cells, as defined by expression of the respective activation marker, is indicated. It becomes obvious that for all of these markers, activated cells could be further subdivided in Fluo-3-extruding and nonextruding subsets. In addition, in each analysis, Fluo-3-extruding cells were identified which stained negative for the respective activation marker and would not have been identified as activated cells by analysis of the respective activation marker alone. Therefore, sorting according to the functional parameter Fluo-3 extrusion defined a unique new subpopulation within CD4+ cells.

\section{Discussion}

Herein we describe a transmembrane transporter which differentiates between resting Th1 and Th2 cell clones. Extrusion of the dye Fluo-3 by this transporter was demonstrated in four out of four resting Th2 cell clones, but was absent or only barely present in four out of four resting Th1 cell clones. The inhibition profile of Fluo-3 efflux suggested that the transporter has characteristics similar to those of MRP protein. Northern and Western blotting studies confirmed that the expression of MRP mRNA and MRP protein in the resting T cell
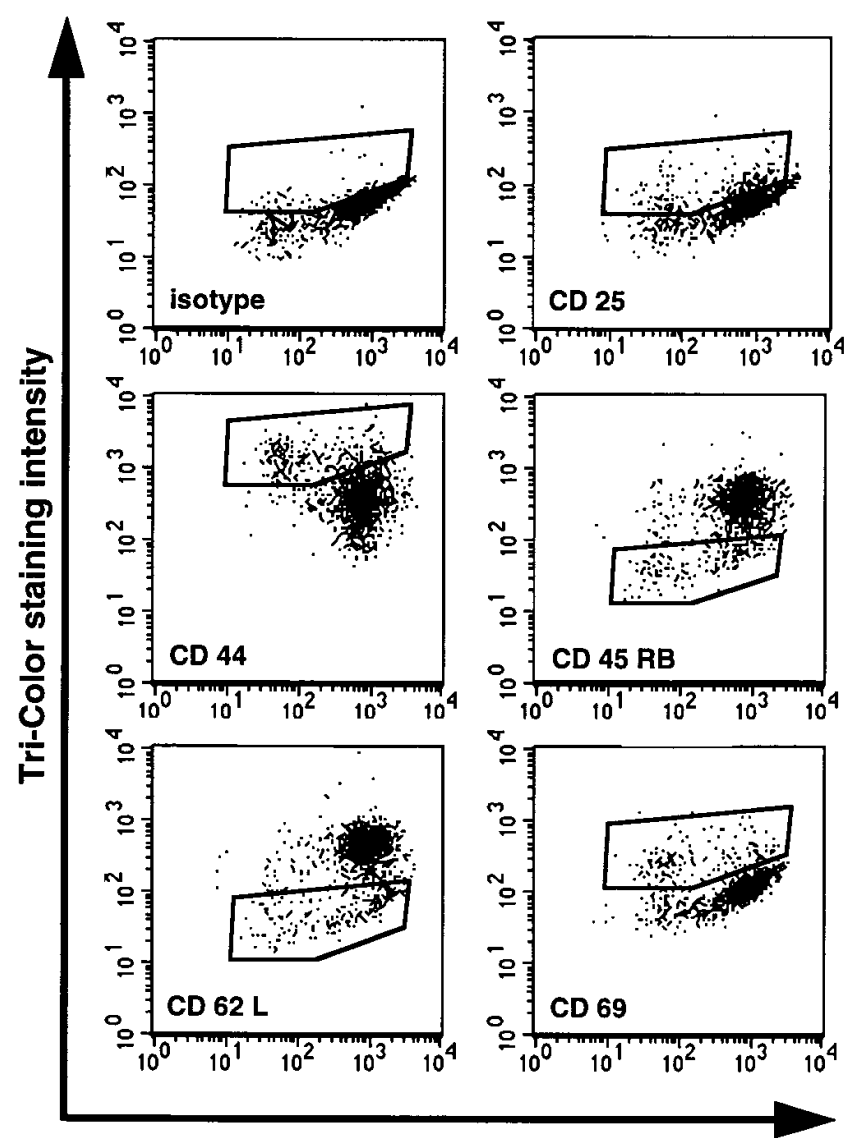

Fluo-3 staining intensity

Figure 8. Flow cytometric analysis by three-color staining to test for a correlation of the presence of the Fluo-3-extruding pump with the expression of the indicated activation markers in CD4+ cells. AntiCD4 and Fluo-3 staining, as well as indirect visualization of the respective activation markers by streptavidin tricolor were performed, as described in Methods. All cells depicted are gated for CD4+ cells. In each panel, the area containing activated cells according to expression of the respective activation marker is indicated.

clones correlated with the capacity to extrude Fluo-3. Why the pump is expressed in resting Th2, but not Th1 cells, and what its physiological substrate might be is presently unknown. Currently, we are testing the hypothesis that $\mathrm{LTC}_{4}$ which has the capacity to block Fluo-3 extrusion (Fig. $2 A$ ) and is a known MRP substrate (36) might be transported by resting Th2, but not Th1 cells.

After antigenic activation, the pump was induced in Th1 cell clones and reached a similar level of expression as in Th2 cell clones. This suggested that Fluo- 3 extrusion might enable the identification of activated Th1 cells and of Th2 cells (resting or activated) ex vivo. Murine cutaneous leishmaniasis (8), caused by the protozoan parasite $L$. major and leading to activation of $L$. major-specific T cells of either Th1 (C57BL/6 mice) or Th2 phenotype (BALB/c mice), was used as an experimental model to address this question. During infection, a Fluo-3-extruding pump was identified within $\sim 2-4 \%$ of $\mathrm{CD} 4+\mathrm{T}$ cells present in the lesion-draining $\mathrm{LN}$ of both $\mathrm{C} 57 \mathrm{BL} / 6$, as well as BALB/c mice. Moreover, sorting of these 
Fluo-3-extruding CD4+ cells proved to be a potent method to select for parasite-specific Th1 or Th2 cells, respectively (Fig. 7).

To our knowledge, this is the second publication that reports sorting of antigen-triggered Th1 or Th2 cells ex vivo according to a functional parameter, i.e., organic anion transport. The other method was described only recently and involves the technically complex staining of lymphokines at the surface of lymphokine-secreting cells (37). It is quite possible that expression of the MRP-like molecule facilitates extrusion of products which are produced particularly by activated cells, such as mediators for other cells or end products of cell metabolism. Sorting according to this functional parameter may provide a more direct enrichment of recently activated antigen-triggered Th1 and Th 2 cells than sorting on the basis of activation markers, many of which (like CD45RO or CD44) persist even when the cells have already been deactivated. While several other reports have described subsets of T cells on the basis of P-glycoprotein rather than MRP expression (38-40), none have investigated Th1 or Th2 cells or T cells that had been activated by antigen in vivo.

Sorting according to Fluo-3 extrusion in combination with expression of activation markers may be even more effective because in triple-color staining experiments the Fluo-3-extruding CD4+ T cell subset within LN of L. major-infected mice did not coincide with subsets defined by expression of CD25, CD44, CD45RB, CD62L, and CD69 (25-29). In addition, the combined expression of activation markers as well as the MRP-like pump may allow the identification of diverse functionally important subpopulations of CD4+ T cells. Therefore, the analysis of Fluo-3 extrusion may be helpful to identify antigen-triggered $\mathrm{T}$ cells in situations of infectious diseases or in autoimmune diseases where the causing antigen is unknown and lymphoid hyperplasia hides the relevant $\mathrm{T}$ cell population.

The finding that resting Th1 and Th2 cells differ with regard to expression of the MRP-like molecule, offers the intriguing possibility of a selective manipulation of the function of these cells in vivo. In humans, this could permit treatment of allergic disorders in periods when the harmful antigen is lacking and Th1 as well as Th2 cells have been restored to a resting state. Also, it may be possible that in vivo application of cytotoxic drugs, e.g., during cancer treatment, leads to a shift of the memory cell population toward Th2 due to the selective continuous presence of the transporter molecule in these cells. However, experimental study of a selective manipulation of either Th1 or Th2 cells in a situation where they coexist clearly awaits establishment of an appropriate animal model. In the animal models that have been used so far for study of Th1 and Th 2 cells in vivo, a polarization to either Th1 or Th2 cells, but not both, is induced in one animal. Also, in most animal models the differentiation of precursor Th cells to Th1 or Th2 is investigated, but not in a situation where these cells are already present at the onset of the study. Studies are ongoing in our laboratory to establish such a model based on murine cutaneous leishmaniasis.

\section{Acknowledgments}

We would like to thank Ms. Susanne Bischof for excellent and patient assistance throughout these studies. We also would like to thank Prof. Keppler, DKFZ, Heidelberg, Germany, for helpful advice and Dr. R. Scheper, Amsterdam, The Netherlands, for mAb MRPr1.

This work was supported by the DFG (SFB 263).

\section{References}

1. Grynkiewicz, G., M. Poenie, and R.Y. Tsien. 1985. A new generation of $\mathrm{Ca} 2+$ indicators with greatly improved fluorescence properties. J. Biol. Chem. 260:3440-3450.

2. Di Virgilio, F., T.H. Steinberg, J.A. Swanson, and S.C. Silverstein. 1988. Fura-2 secretion and sequestration in macrophages. A blocker of organic anion transport reveals that these processes occur via a membrane transport system for organic anions. J. Immunol. 140:915-920.

3. Sommer, F., S. Bischof, M. Rollinghoff, and M. Lohoff. 1994. Demonstration of organic anion transport in T lymphocytes. L-lactate and fluo-3 are target molecules. J. Immunol. 153:3523-3532.

4. Kartner, N., J.R. Riordan, and V. Ling. 1983. Cell surface P-glycoprotein associated with multidrug resistance in mammalian cell lines. Science. 221:12851288.

5. Cole, S.P., G. Bhardwaj, J.H. Gerlach, J.E. Mackie, C.E. Grant, K.C Almquist, A.J. Stewart, E.U. Kurz, A.M. Duncan, and R.G. Deeley. 1992. Overexpression of a transporter gene in a multidrug-resistant human lung cancer cell line [see comments]. Science. 258:1650-1654.

6. Betz, M., and B.S. Fox. 1991. Prostaglandin E2 inhibits production of Th1 lymphokines but not of Th2 lymphokines. J. Immunol. 146:108-113.

7. Munoz, E., A.M. Zubiaga, M. Merrow, N.P. Sauter, and B.T. Huber. 1990. Cholera toxin discriminates between T helper 1 and 2 cells in T cell receptor-mediated activation: role of cAMP in T cell proliferation. J. Exp. Med. 172: 95-103.

8. Reiner, S.L., and R.M. Locksley. 1995. The regulation of immunity to Leishmania major. Annu. Rev. Immunol. 13:151-177.

9. Lohoff, M., E. Schmitt, A.B. Reske Kunz, and M. Rollinghoff. 1990. Different response of TH1 cells for stimulation with anti-CD3 antibodies. Eur. J. Immunol. 20:653-658.

10. Schmitt, E., R. Van Brandwijk, J. Van Snick, B. Siebold, and E. Rude. 1989. TCGF III/P40 is produced by naive murine CD4+ T cells but is not a general T cell growth factor. Eur. J. Immunol. 19:2167-2170.

11. Lohoff, M., C. Matzner, and M. Rollinghoff. 1988. Polyclonal B-cell stimulation by L3T4+ T cells in experimental leishmaniasis. Infect. Immun. 56: 2120-2124.

12. Plachov, D., H.G. Fischer, A.B. Reske Kunz, and E. Rude. 1988. The specificity of the interaction between the agretope of an antigen and an Ia-molecule can depend on the T cell clonotype. Mol. Immunol. 25:611-620.

13. Kaye, J., S. Gillis, S.B. Mizel, E.M. Shevach, T.R. Malek, C.A. Dinarello, L.B. Lachman, and C.A. Janeway, Jr. 1984. Growth of a cloned helper $\mathrm{T}$ cell line induced by a monoclonal antibody specific for the antigen receptor: interleukin 1 is required for the expression of receptors for interleukin 2. J. Immunol. 133:1339-1345.

14. Lohoff, M., M. Steinert, A. Weiss, M. Rollinghoff, R.S. Balderas, and A.N. Theofilopoulos. 1994. V beta gene repertoires in T cells expanded in local self-healing and lethal systemic murine cutaneous leishmaniasis. Eur. J. Immunol. 24:492-495.

15. Solbach, W., K. Forberg, E. Kammerer, C. Bogdan, and M. Rollinghoff. 1986. Suppressive effect of cyclosporin A on the development of Leishmania tropica-induced lesions in genetically susceptible BALB/c mice. J. Immunol. 137:702-707.

16. Karasuyama, H., and F. Melchers. 1988. Establishment of mouse cell lines which constitutively secrete large quantities of interleukin 2, 3, 4 or 5, using modified cDNA expression vectors. Eur. J. Immunol. 18:97-104.

17. Miltenyi, S., W. Muller, W. Weichel, and A. Radbruch. 1990. High gradient magnetic cell separation with MACS. Cytometry. 11:231-238.

18. Grant, C.E., G. Valdimarsson, D.R. Hipfner, K.C. Almquist, S.P. Cole, and R.G. Deeley. 1994. Overexpression of multidrug resistance-associated protein (MRP) increases resistance to natural product drugs. Cancer Res. 54:357-361.

19. Hipfner, D.R., S.D. Gauldie, R.G. Deeley, and S.P.C. Cole. 1994. Detection of the Mr 190,000 multidrug resistance protein MRP, with monoclonal antibodies. Cancer Res. 54:5788-5792.

20. Flens, M.J., M.A. Izquierdo, G.L. Scheffer, J.M. Fritz, C.J. Meijer, R.J. Scheper, and G.J. Zaman. 1994. Immunochemical detection of the multidrug resistance-associated protein MRP in human multidrug-resistant tumor cells by monoclonal antibodies. Cancer Res. 54:4557-4563.

21. Kartner, N., D. Evernden Porelle, G. Bradley, and V. Ling. 1985. Detection of P-glycoprotein in multidrug-resistant cell lines by monoclonal antibodies. Nature. 316:820-823.

22. Dalton, W.S., B.G. Durie, D.S. Alberts, J.H. Gerlach, and A.E. Cress. 1986. Characterization of a new drug-resistant human myeloma cell line that expresses P-glycoprotein. Cancer Res. 46:5125-5130.

23. Loe, D.W., K.C. Almquist, S.P. Cole, and R.G. Deeley. 1996. ATPdependent 17 beta-estradiol 17-(beta-D-glucuronide) transport by multidrug resistance protein (MRP). Inhibition by cholestatic steroids. J. Biol. Chem. 271: 9683-9689.

24. Ortega, G., R.J. Robb, E.M. Shevach, and T.R. Malek. 1984. The murine IL 2 receptor. I. Monoclonal antibodies that define distinct functional epitopes on activated T cells and react with activated B cells. J. Immunol. 133: 1970-1975.

25. Cantrell, D.A., and K.A. Smith. 1984. The interleukin-2 T-cell system: a 
new cell growth model. Science. 224:1312-1316.

26. Budd, R.C., J.C. Cerottini, C. Horvath, C. Bron, T. Pedrazzini, R.C. Howe, and H.R. MacDonald. 1987. Distinction of virgin and memory T lymphocytes. Stable acquisition of the Pgp-1 glycoprotein concomitant with antigenic stimulation. J. Immunol. 138:3120-3129.

27. Birkeland, M.L., P. Johnson, I.S. Trowbridge, and E. Pure. 1989. Changes in CD45 isoform expression accompany antigen-induced murine T-cell activation. Proc. Natl. Acad. Sci. USA. 86:6734-6738.

28. Gallatin, W.M., I.L. Weissman, and E.C. Butcher. 1983. A cell-surface molecule involved in organ-specific homing of lymphocytes. Nature. 304:30-34

29. Yokoyama, W.M., F. Koning, P.J. Kehn, G.M. Pereira, G. Stingl, J.E. Coligan, and E.M. Shevach. 1988. Characterization of a cell surface-expressed disulfide-linked dimer involved in murine $\mathrm{T}$ cell activation. J. Immunol. 141: 369-376.

30. Lefkovits, I., and H. Waldmann. 1984. Limiting dilution analysis of the cells of immune system. I. The clonal basis of the immune response. Immunol. Today. 5:265-268.

31. Stride, B.D., G. Valdimarsson, J.H. Gerlach, G.M. Wilson, S.P.C. Cole, and R.G. Deeley. 1996. Structure and expression of the mRNA encoding the murine multidrug resistance protein (MRP), an ATP-binding cassette transporter. Mol. Pharmacol. 49:962-971.

32. Boesch, D., K. Muller, A. Pourtier Manzanedo, and F. Loor. 1991. Restoration of daunomycin retention in multidrug-resistant P388 cells by submicromolar concentrations of SDZ PSC 833, a nonimmunosuppressive cyclosporin derivative. Exp. Cell Res. 196:26-32.

33. Barrand, M.A., T. Rhodes, M.S. Center, and P.R. Twentyman. 1993.
Chemosensitisation and drug accumulation effects of cyclosporin A, PSC-833 and verapamil in human MDR large cell lung cancer cells expressing a 190k membrane protein distinct from P-glycoprotein. Eur. J. Cancer. 29A:408-415.

34. Endicott, J.A., and V. Ling. 1989. The biochemistry of P-glycoproteinmediated multidrug resistance. Annu. Rev. Biochem. 58:137-171.

35. Georges, E., F.J. Sharom, and V. Ling. 1990. Multidrug resistance and chemosensitization: therapeutic implications for cancer chemotherapy. Adv. Pharmacol. 21:185-220.

36. Leier, I., G. Jedlitschky, U. Buchholz, S.P.C. Cole, R.G. Deeley, and D. Keppler. 1994. The MRP gene encodes an ATP-dependent export pump for leukotriene $\mathrm{C}_{4}$ and structurally related conjugates. J. Biol. Chem. 269:2780727810.

37. Manz, R., M. Assenmacher, E. Pfluger, S. Miltenyi, and A. Radbruch. 1995. Analysis and sorting of live cells according to secreted molecules, relocated to a cell-surface affinity matrix. Proc. Natl. Acad. Sci. USA. 92:1921-1925.

38. Lalande, M.E., V. Ling, and R.G. Miller. 1981. Hoechst 33342 dye uptake as a probe of membrane permeability changes in mammalian cells. Proc. Natl. Acad. Sci. USA. 78:363-367.

39. Bommhardt, U., J.C. Cerottini, and H.R. MacDonald. 1994. Heterogeneity in P-glycoprotein (multidrug resistance) activity among murine periphera T cells: correlation with surface phenotype and effector function. Eur. J. Immunol. 24:2974-2981.

40. Abbaszadegan, M.R., B.W. Futscher, W.T. Klimecki, A. List, and W.S. Dalton. 1994. Analysis of multidrug resistance-associated protein (MRP) messenger RNA in normal and malignant hematopoietic cells. Cancer Res. 54: 4676-4679. 